Revista de Filosofía y Teoría Política, n. ํ 49, 2018, e016, ISSN 2314-2553

Universidad Nacional de La Plata.

Facultad de Humanidades y Ciencias de la Educación.

Departamento de Filosofía

\title{
Bitácora de lo político. El secreto entre la razón de Estado y la ilustración
}

\section{Leonardo Daniel Eiff}

CONICET; Universidad Nacional de General Sarmiento, Argentina leoeiff@yahoo.com.ar

Cita sugerida: Eiff, L. D. (2018). Bitácora de lo político. El secreto entre la razón de Estado y la ilustración. Revista de Filosofía y Teoría Política, (49), e016. https://doi.org/10.24215/23142553e016

Recibido: 30 mayo 2017 - Aceptado: 08 mayo 2018 - Publicado: 01 noviembre 2018

(c) (1) (2) (2) Esta obra está bajo licencia Creative Commons Atribución-NoComercial-CompartirIgual 4.0 Internacional cc) (1) (2) http://creativecommons.org/licenses/by-nc-sa/4.0/deed.es_AR 


\section{Bitácora de lo político. El secreto entre la razón de Estado y la ilustración}

\section{Boussole du politique. Le secret entre la raison d'État et les lumières}

Leonardo Daniel Eiff

CONICET; Universidad Nacional de General Sarmiento, Argentina

leoeiff@yahoo.com.ar

\section{ReSUMEN:}

El presente trabajo indaga las relaciones entre la política y el secreto desde las discusiones y polémicas en torno al Estado. Su tema es el entrelazo entre lo político y el Estado. Para ello, procura reconstruir una constelación de lecturas sobre la razón de Estado e identifica en la crítica ilustrada el mayor desafío a dichas razones. La cuestión del secreto orienta el recorrido a través de los estudios sobre la razón de Estado y ubica a la ilustración en el vértice entre la transparencia y el arcano. Finalmente, el trabajo plantea algunas sugestiones teóricas sobre la política argentina tras la crisis del 2001.

Palabras Clave: Político, Arcano, Estado, Transparencia, Ilustración.

\section{RÉSUMÉ:}

Le travail présent recherche les relations entre la politique et le secret à partir des discussions et les polémiques autour de l'État. Son sujet c'est l'entrelacs entre le politique et l'État. Pour cela, il essaie de reconstruire une constellation de lectures sur la raison d'État et identifie dans la critique illustrée le plus grand défi aux dites raisons. La question du secret oriente le parcours à travers des études de la raison d'État. Le texte place à l'illustration dans le sommet entre la transparence et l'arcane. Finalement, le travail projette quelques suggestions théoriques sur la politique argentine après la crise de 2001.

Mots CLÉs: Politique, Arcane, État, Transparence, Lumières.

Le secret est l'âme des affaires publiques.

Aubery

\section{INTRODUCCIÓN}

Entre la alabanza y el vituperio la política atraviesa los senderos del secreto. Elogio de los que hacen de la necesidad virtud y conciben la opacidad como un momento ineludible de la acción política o del propio funcionamiento de la maquinaría estatal y reproche en aquellos que consideran la apelación a la necesidad como una artimaña para justificar la existencia de una elite que monopoliza la decisión política a fin de garantizar un régimen de dominio. Estamos, sin duda, ante uno de los nervios medulares de la vida social; entre, parafraseando el título de un famoso libro, la transparencia y el obstáculo. ¿Es factible transparentar el conjunto de las relaciones sociales? Volverlas previsibles, cristalinas, emancipadas de las confabulaciones nocturnales, de los traficantes de rumores, de la ideología del interés. Nuestros tiempos postseculares (Palti, 2005), postfundacionales (Marchart, 2009), aunque también la modernidad madura como revelan los clásicos de las ciencias sociales (Simmel, 1939), descartarían rápidamente tales intentos, puesto que, como sabemos, lo social entraña un reducto indecible - lo real, dirían los que acostumbran a menear a Lacan - que no puede ser revelado; quienes lo intentaron reprodujeron dogmas ideológicos o ficciones totalitarias, el discurso del amo. En fin, no vale la pena procurar una sociedad transparente, más allá del secreto, siquiera es deseable. Los que insisten reponen una ilusoria moral ilustrada y manifiestan su incompetencia teórica y política. Sin 
embargo, la aceptación perspicaz, incluso adornada estéticamente, del secreto como lo irreductible, ronroneo ineliminable en la interfaz de lo social, adquiere singularidad cuando enraizamos dicho consenso de época en el vínculo moderno entre lo político y el Estado. El Estado es lo sospechado, quien oculta (intereses, políticas, complots, responsabilidades), desvía, expone y crea narraciones para vedar sus acciones reales, reproductivas de un orden social injusto. Como si el lenguaje estatal se condensara en la conocida frase de Talleyrand: la parole a été donnée à l'homme pour déguiser sa pensée. Al hombre de estado, vale rectificar. Herederos de los "maestros de la sospecha", nos empeñamos en criticar-develar el secreto sempiterno del Leviatán: la universalidad declamada es una máscara simbólica y material de su auténtica condición de resguardo de las relaciones de dominación. He aquí unas de las paradojas teórico-políticas de nuestro tiempo (el de las muertes anunciadas, la proliferación de "post" y "neo" y el recurrente estallido de subjetividades dispersas, hojaldradas): contra la transparencia liberal-ilustrada destacamos "lo indecible último", la valencia opaca del secreto en la estructuración del entramado social y político, pero, por otra parte, insistimos con la denuncia ilustrada de la razón de Estado, que antaño enlazó la universalidad estatal y el secreto de sus razones, concebida como falsa totalidad. Recorrer nuestra relación paradójica con el Estado motivó este artículo, aunque lo haremos dando un "salto hacia atrás"

En efecto, nuestro trabajo pretendemos reflexionar sobre el anudamiento entre el secreto y la política restañando algunos debates suscitados en la modernidad clásica a partir del contraste entre la razón de Estado y el movimiento de la ilustración. La temática es amplísima, estamos ante uno de los nudos que forjaron el Estado nacional moderno -y su crítica, democrática primero, socialista después-, la bibliografía vasta. Los conocidos trabajos de Norberto Bobbio (2013) en torno al problema del sottogoverno cifran su criticidad en la compleja relación entre razón de Estado y democracia, y apuestan por una continua e interminable ampliación de la luz pública enraizada en el acotamiento jurídico del poder estatal y acompañada por una sociedad civil movilizada que pugna por ensanchar la esfera de publicidad del poder. Escritos en el clima democrático de los años 80 y en el marco de la ya lacerante crisis del sistema político italiano de posguerra, Bobbio se inclina por las razones jurídico-políticas antes que por las político-estatales (volveremos sobre ello en la conclusión). En cambio, nosotros pretendemos ser menos rígidos en la contraposición y destacar las pasarelas entre el "Estado" y el "derecho". En este sentido, procuramos achicar el ángulo de toma concentrándonos en tres instancias que, como destellos, nos permitirán asir la problemática, con sus vericuetos y préstamos. En primer lugar, analizaremos algunos estudios en torno a la razón de Estado realizados en el siglo XX, cuyo discurrir entre guerras absolutas, revoluciones, totalitarismos, pusieron en entredicho la validez de la racionalidad estatal. Desde los trabajos históricos de Friedrich Meinecke (1959) y Etienne Thuau (2000) hasta los análisis genealógicos y genéticos de Michel Foucault (2004) y Pierre Bourdieu (2014), nos proponemos resaltar el entrelazo entre política y secreto cincelado en el arte de gobernar el Estado. En segundo lugar, indagaremos la polémica alrededor de los modos legítimos de las acciones bélicas; qué se puede realizar y qué no durante el transcurso de la guerra. El trabajo jurídico de las distinciones. En fin, el arte secreto de la guerra y el afán de transparentar y acotar sus efectos a través de un encuadre legal en el marco de un sistema inter-estatal de equilibrio. En tercer lugar, pondremos a consideración la crítica ilustrada a la razón de Estado realizada en nombre de la nitidez del derecho y el mercado. Los derechos naturales y positivos y la sociedad de mercado tornan innecesarios los artificios estatales, con sus consecuencias a menudo belicosas. El derecho y el mercado ponen coto al monopolio de lo político y a su momento eminente: la decisión soberana. Se trata de encuadran y sintetizar esta vasta construcción moderna alrededor de la cuestión del secreto. Para ello hilvanamos una lectura de Critica y crisis de Reinhart Koselleck y su manera de indagar la enrevesada politicidad de la ilustración. También los trabajos de Pierre Rosanvallon (1999) y Karl Polanyi (1988) sobre la institución de la sociedad de mercado. Con todo, veremos la crítica del secreto como critica de la política, con sus pliegues, flecos y dobleces. Finalmente, concluiremos con una serie de interrogantes que emanan del vínculo propuesto en un ya muy desarrollado contexto epocal de disolución de la estatalidad, cuya apuesta ético-política medular reside, sin embargo, "en un deber en pro del Estado" (Schmitt, 2012, p.305). 


\section{LA ESTRELLA POLAR DE LA POLITICA MODERNA}

Jorge Dotti estampó en la presentación de la revista Deus Mortalis la siguiente y definitiva declaración: "filosofar políticamente es, ante todo, filosofar sobre el Estado y sobre lo que, paradójicamente, inmortaliza humanamente al 'dios mortal'” (Dotti, 2002). La serie de escritos dedicados al concepto de razn de Estado pueden considerarse como uno de los momentos cumbres de esa reflexión filosófico-política consagrada al Estado. En un contexto bisagra, entre la guerra civil religiosa europea -que liquidó la Repblica Cristianay la subsiguiente erección de la paz absolutista que neutralizó las pasiones político-religiosas produciendo una nítida distinción entre Estado y sociedad, pblico y privado, la promoción de la razón de Estado es una respuesta a la crisis terminal del universalismo cristiano. Asimismo, emerge en un clima espiritual de fuerte religiosidad, agonal, producto del cisma de la Reforma. En suma, los escritos sobre la razón de Estado (herederos de, pero también en ruptura con, los tradicionales “espejos de príncipes”) serán retomados por los arquitectos del Estado centralizado, cuya divisa recalará en la superioridad ética y política de la estatalidad frente a cualquier otra forma de agrupamiento humano.

Ahora bien, el clímax de la crisis, lealtades cruzadas entre la fe religiosa y la obediencia a las leyes del reino que obligaba al sigilo, a la cautela, se condensa sin embargo en un nombre escandaloso, objeto de acusación, fronterizo entre lo público y el arcano: Niccolò Machiavelli. Maquiavelo coagula los debates en torno a la razón de Estado. Aunque el término no aparece en sus escritos (la expresión "razón de Estado" surge limpia en un escrito de Giovanni Botero ${ }^{1}$ ), "El Príncipe" es sindicado como testimonio cabal de ese nuevo arte de la política. Pues bien, entre la disolución de un orden político, la construcción de otro calibrado alrededor de un "dios mortal", y la figura liminar de Maquiavelo, sugiero considerar algunos aspectos de la razón de Estado, menos en su especificidad histórica ${ }^{2}$ que en sus efectos para la pregunta medular que atravesó el siglo $\mathrm{XX}$ : ¿qué es la política?

Comienzo por dos estudios históricos dedicados a la problemática. El primero, La idea de la razón de Estado en la edad moderna (1959), data de 1924 y fue escrito por Friedrich Meinecke. Historiador político, defensor e impulsor del Kulturstaat contra el Estado liberal decimonónico (Real Alcalá, 2011), su libro sobre la razón de Estado es una vindica de la Alemania derrotada, culpabilizada y sometida a un trato humillante como resultado de la paz de Versalles. También es una reflexión crítica sobre los excesos de la "política de poder" alemana, que tuvo, como era notorio en 1924, efectos contraproducentes. Maquiavelo, Federico el Grande y Hegel son las naves insignias que hacen justicia a la Idea. En efecto, entre el historicismo decimonónico y el idealismo absoluto, la razón de estado se concibe en la perspectiva de lo histórico-espiritual (geistesgeschichtlich) en liza con la weltanschauung liberal. Lectura política entonces, pero también una fina reconstrucción histórica del nacimiento del Estado moderno - con el sesgo evidente de la historia espiritual alemana-, que no sólo atiende a los grandes procesos históricos y los principales sistemas teóricos, Bodin y Hobbes v.g, sino que restaña escritos menores, de oscuros funcionarios y cortesanos, que, sin embargo, aceitaron la maquinaria estatal moderna. La medula del estudio reside en la doble valencia de la razón de Estado: imprescindible para que la acción política produzca un orden existencial concreto e ineliminable su acechante rasgo demoníaco. Racionalidad superior y descenso a los infiernos. Vieja cuestión protestante: el problema del mal. Es, se sabe, uno de los cogollos de la obra de su contemporáneo Max Weber, aquí circunscripto al despliegue de la razón de Estado y a la sombra terrible de su inventor: Maquiavelo.

"Razón de Estado es la máxima del obrar político, la ley motora del Estado. La razón de Estado dice al político lo que tiene que hacer, a fin de mantener al Estado sano y robusto” (Meinecke, 1959, p.3). Así inicia el libro, con un intento de precisión conceptual a fin de sustraer a la razón de Estado de cualquier ligazón con el capricho dictatorial. El obrar político tiene el norte del orden estatal, la razón de Estado es un concepto en sentido hegeliano, que se autodespliega a través de la autonconciencia de los políticos; es la teoría rectora de una praxis regida por la necesidad. Meinecke parte de un reconocimiento: el poder es la esencia del Estado. Su Razón morigera, amortigua, la magnitud objetiva, a menudo desbordante, del 
poder. La razón de Estado es la traducción moderna de la prudencia antigua. No obstante, la prudencia es un ligamen entre la ética y la política que responde a una cosmovisión actuante, que yace resquebrajada en los tiempos de la "muerte de Dios". Como decíamos, el tema del libro es la relación entre ética y política y entre política e historia configurado en términos maquiavelianos (virtü) y hegelianos (eticidad). Los únicos válidos en la modernidad, pero lastimosos para la religiosidad de Meinecke (espejada en la de Ranke), quien acaba afirmando la insuperabilidad del dualismo entre ethos y cratos, entre Dios y el Estado. En suma, la estatalidad es catejóntica.

Trabajar en secreto: "este es el idioma imperativo de la razón de Estado" (Meinecke, p.307). Las máscaras, los dobleces, el confirmar explícitamente máximas para socavarlas implícitamente, acompañan a la galería de personajes políticos, cortesanos e intelectuales, que pueblan el libro. Caso testigo: Federico el Grande. Escribió una famosa diatriba contra Maquiavelo en nombre de la moral cristiana, las buenas costumbres y la razón ilustrada; sin embargo, su política de estado es palmariamente maquiaveliana; sus escritos buscan disimularlo con éxito dispar. La razón de Estado está obligada al secreto porque debe ocultar el carácter irreconciliable de la política y la moral. Declararse cristianos, piadosos, para luego practicar o ponderar una política emancipada de los principios morales hegemónicos, considerados inaplicables en el reino del Estado. El problema radica en que la racionalidad política del Estado no puede permanecer despojada de moralidad; de allí que se vuelva imperioso hallar otra moral, pública, patriótica, asociada al bien común; pero con qué referencias, con cuál escala de valores (Maquiavelo siempre sinuoso, en este punto es menos claro aún). La vieja moral vuelve a colarse cuando se intenta dotar al poder de Estado de una dimensión ética; la rueda vuelve a girar y el drama recomienza. No hay superación del dualismo. Pero nadie está cómodo en él. Por eso, mientras se ofrecen sucesivamente universales de reconciliación, la razón de Estado trabaja en secreto, dinamitando puentes y poniendo a los actores ante la disyuntiva de elegir: Dios o el Estado. Meinecke desea que el hombre de Estado lleve a ambos en su pecho, pero sabe que, a veces, situaciones demoníacas compelen a optar. El arcano, el drama interior de la conciencia política decisoria, ahorra compromisos y da margen, permite surcar el acontecimiento. El arte político de la razón de Estado discurre en secreto.

"La estrella polar de la política moderna" (Conring) fue sometida a un nuevo estudio histórico, en este caso centrado en la Francia de Richelieu: Raison d'État et pensé politique à l'époque de Richelieu (Thuau, 2000). Se trata de un libro, a diferencia del de Meinecke, de estricta factura historiográfica, ${ }^{3}$ que se propone reconstruir la urdimbre de la literatura política de comienzos del Siglo XVII en su momento agonal: disolución del universalismo cristiano y construcción de la legitimidad estatal. El bordado se realiza hilvanando las polémicas político-intelectuales entre el partido de la religión y los partidarios del Estado. Los primeros defienden la primacía de la moral religiosa contra los "políticos", la alianza católica de Francia con España y denuestan la tiranía del Cardenal Richelieu; los segundos denuncian el uso político-partidario de la religión, postulan la unión de la política con la religión a través de la superioridad del orden estatal, que es, por supuesto, indiscernible de la defensa y alabanza del gobierno del Cardenal. El triunfo de los segundos abrió la brecha de la secularización con una serie de ambigüedades, que Thuau, historiador ilustrado, puntualiza. La primera es que el progreso de la razón, cuya divisa política es la disolución de la "sociedad de cuerpos" (el autor no se priva de adjetivar casi siempre negativamente la retórica de los catholiques zélés), esconde la erección de un régimen autoritario a través del fomento de las virtudes de la obediencia, que, sin duda, lastiman el progreso de la razón. La segunda entraña el problema de la legitimidad del Estado en vías de secularización. Estará a cargo del Rey por derecho divino, pero ya sin el marco bíblico y eclesial, sino por su propia autoritas regia. La solución es teológico-política. Thuau advierte un contraste explosivo. El juego de préstamos entre la teología y la política, encarnada, por otra parte, en la figura egregia del Cardenal, es crucial en la serie de escritos, panfletos, posturas y prácticas que Thuau llama "le courant étatiste". En efecto, la razón de Estado es considerada, contra los católicos-devotos que la bautizaron como "razón del infierno", una "razón divina". Contrariedades, o vaivenes, en todo caso, resabios teológicos y autoritarios que acompañaron la iniciática cristalización del Estado, cuya remoción estará a cargo del movimiento de la ilustración y la 
triunfante sociedad burguesa. Queda irresuelta la cuestión de la vigencia de la razón de Estado: ¡es propia del Estado absolutista o persiste bajo el Estado burgués?

De todas formas, la ambigüedad intenta traducir una noción que, por el revés de la trama, nubla la luminosidad de una transición histórica. "la obsesión por el secreto caracteriza la literatura política de la primera mitad del Siglo XVII" (Thuau, p.40). El romano Tácito, leído como un historiador de la razón de Estado, será considerado "el maestro de los secretos de Estado" (Thuau, p.40). En el mismo sentido se ponderará, también secretamente, a Maquiavelo. La corriente humanista y neoestoica hará de la disimulación honesta (Acceto, 2005; Bodei, 1997, pp.139-49) un conjunto de prácticas de cautela frente al poder teológico y político. En cambio, los impulsores de la razón de Estado intentaran, guiados por ella, conocer los secretos de la dominación; los arcana imperii (tomado de los Annales), que, en el lenguaje de la época, eran asimilados a los coups d'État -así se titulaba el afamado libro de Gabriel Naudé (Thuau, p.324). Variante política de la alquimia, la literatura que analiza Thuau gira en torno al problema de la obediencia tras el derrumbe de los modos tradicionales, piadosos, de comulgar con el orden. ¿Cómo gobernar los espíritus? Gobernar, es hacer creer. Richelieu pergeña un gabinete de prensa y lubrica una maquinaria propagandística enfocada en defender su política y denostar a sus detractores. Allí se elabora una retórica estatal, del orden público, la soberanía absoluta y el poder protector directo, contra los partidarios del extranjero, de España, disfrazados de religiosos, los sediciosos que admitían el derecho de matar al tirano (jesuitas), y los que validaban una autoridad por encima o limitante de la regia. Constelación de "intelectuales" cortesanos, que reúnen las artes y la política (la creación de l'Académie française forma parte de este proyecto) en pos del Cardenal; mecenas, impulsor y garante de lo que luego Bourdieu llamará nobleza de Estado. Thuau se demora en la indagación de estos textos, los desempolva para iluminar la forja del Estado, hermanado con el proceso de autonomización de la política, pero es reacio al secreto, puesto que discurre del vituperable costado de la dominación y la obediencia. Así, el secreto se justifica en el cinismo, la hipocresía, en el desprecio al pueblo, incapaz de comprender las razones de la política. En su "necesidad" ambiciona guarecerse en la novísima autoridad de una elite estatal creada al amparo de la política del Cardenal rojo.

Hay otra manera de elucidar la contrariedad. Los secretos de la dominación, la obsesión política del siglo inaugural de la modernidad, traducen, acaso no del todo bien, el arcano de la soberanía. La plenitudo potestatis es sostenida en, y por, la decisión. El problema radica en que no se puede publicitar su legitimidad recostándose en el mero arbitrio soberano; su fomento exige, por el contrario, abrirse a un fundamento trascendente. Desde los dos cuerpos del rey, la razón de Estado, las variantes naturalistas, positivistas, cosmopolitas e historicistas del derecho, hasta la consagración del mercado autoregulado, el poder se admite si encuentra una legitimidad otra. Jamás en su mismisidad. Entonces, menos secretos de la dominación que el secreto cadente del poder. Demasiado despojada en su albor, ponderar la soberanía estatal requiere agudizar las astucias, en liza con teólogos y humanistas, para camuflar su cifra.

La razón de Estado, proveniente de la política principesca italiana y prolongada convenientemente hasta la Roma imperial narrada por Tácito, ofrece la posibilidad de inscribir la legitimidad del poder protector en la necesidad. Un texto cortesano, que Thuau se ocupa de condesar, dramatiza, imaginando los dilemas que habitan la conciencia de Richelieu, la apuesta:

Quel a été dans son âme le combat de la nécessité despeuples et de celle des affaires. L'issu de ce combat n' est guère douteuse chez un politique comme Richelieu: il doit suivre la raison d'État ou, en d'autres termes, obéir à la nécessité. Les gouvernants sont les hérauts et les serviteurs de la nécessité (Thuau, p.249-50).

Tanto Michel Foucault como Pierre Bourdieu emplean casi exclusivamente el estudio de Thuau cuando se abocan a reflexionar sobre la razón de Estado. Al igual que el historiador, la consideran medular para atisbar el nuevo modo de gobernar y de legitimar el ejercicio del poder tras el estallido de la política cristiana. En rigor, Foucault y Bourdieu desencapsulan el concepto de su anclaje italiano y lo llevan al nudo de lo moderno, a las 
relaciones entre gobierno y Estado, a las astucias de la dominación. Para ello, se sirven, sobre todo el filósofo, del muy francés libro de Thuau (Foucault, 2004, p.283; Bourdieu, 2014, p.351).

De todas formas, en el curso Seguridad, territorio, población, Foucault se aleja de los estudios clásicos dedicados a la raison d'État, como los de Meinecke y Thuau, enfatizando en la razón antes que en el Estado. Se trata, como se sabe, de inscribir al Estado en una historia de la gubernamentalidad a fin de despojarlo de sus atributos metafísicos, de su ontología circular, esto es, de abrirlo a la cuestión concreta del gobierno de los hombres. La llamada razón de Estado es un conjunto de técnicas políticas específicas que pretenden responder a la pregunta: "¿a qué racionalidad debe apelar el soberano para gobernar?” (Thuau, p.270) El fin de la analogía y la cifra impiden postular simetrías con el gobierno de la familia o con el pastoral; hay que identificar la singularidad de un arte de gobernar, desligado de los presupuestos teológicos y jurídicos de la soberanía. La razón de Estado fue la consecuencia innovadora de dicha peripecia y, como la física galileana Foucault insiste en el quiasmo entre las concepciones modernas de la naturaleza y el Estado-, su invención trastocó certezas y causo alboroto, un escándalo moral. Lo prueba la profusa literatura anti-maquiavelica; para conocerla, Foucault nos remite a Thuau.

Interesa retener la asociación foucaultiana entre razón de Estado y razón gubernamental: "el Estado es la idea reguladora de la razón gubernamental (...) Principio de inteligibilidad y objetivo estratégico: a mi parecer, esto propone su marco a la razón gubernamental que se denomina precisamente razón de Estado" (Foucault, p.329). Foucault alienta un desplazamiento, para escabullirse del cacareo fóbico en torno al monstruo frío que tapa todos los poros de la sociedad, cuyo consecuencia es una inversión: no es el Estado el que encuentra su razón, la autonomía de la política, sino que es la razón, orientada al gobierno de los hombres, la que hace del Estado su objetivo y, así, lo torna pensable. Corrimiento del foco y por ende de los actores. Ya no se trata de la fundamentación de la soberanía, cuestión jurídica o teológico-jurídica, sino del funcionamiento del gobierno, cuestión política o de los políticos. Estos últimos, "los políticos" (Thuau, 2000, p.10), objeto de las diatribas de los opositores a la "razón del infierno"; agentes de satán, cuyo ministro predilecto es el secretario florentino, quienes serán los encargados de afinar y consolidar este nuevo arte de gobernar (Foucault, 2004, p.289). ¿Cómo? Maquiavelo, tan mentado, no ofrece demasiadas respuestas; su nuevo príncipe no es un "príncipe moderno" ((Foucault, pp.115-16, pp.284-87). El problema ya no es el lazo lábil entre el príncipe y su principado, sino el modo de gobernar lo que más adelante se conocerá como la población. La amenaza ya no proviene de los Grandes sino del pueblo. Se trata de conducir esa nueva fuerza a fin de evitar desbordes. Dos maneras. La primera, remite directamente al estudio de Thuau sobre el gabinete de prensa de Richelieu: "gobernar, es hacer creer". El Cardenal organiza la propaganda política manifestando una aguda preocupación por los vericuetos de la opinión; el gobierno organiza el consenso (Thuau, 2000, pp.169-77). La segunda, recostada en los trabajos de Bacon, destaca los inicios del gobierno económico: crear, administrar y distribuir las riquezas se transforma en un objetivo crucial de los gobernantes. En fin, la economía y la opinión son los correlatos del gobierno, la realidad que debe enfrentar (Foucault, 2004, p.319).

El movimiento foucaultiano alumbra otro rasgo de la razón de Estado: no tanto su enjambre con la cuestión de la soberanía, la "política trascendental", sino, antes bien, la legitimación que provee para prácticas concretas de gobierno, urgidas en responder los desafíos cotidianos de la gubernamentalidad, que, si bien todavía no ha desplegado su potencia, puesto que el tema explícito de la razón de Estado es el Estado y no la población, parece anunciar esa nueva racionalidad. En este sentido, uno de los efectos del desplazamiento se alumbra en el menoscabo de cualquier relación entre el secreto y el arcano de la soberanía. El primero es entrevisto en el marco corriente de los arcana imperii. La trama del poder supone una dialéctica entre lo que debe y lo que no debe ser divulgado. Los recursos, las fuerzas del Estado no pueden ser totalmente públicas porque beneficiaría a los rivales ((Foucault, p.322). Lo mismo ocurre con el golpe de Estado: debe tramarse en secreto hasta su irrupción fulgurante en la escena pública ((Foucault, p.307). La necesidad del secreto es táctica, insumos para el ejercicio del poder. No mucho más. Sin embargo, Foucault, quien pretende pensar el Estado eximido de cualquier remisión al filósofo de Malmesbury, deja dos sugestiones cercanas a la politicidad medular del 
secreto, que, sin ser arcano, son dificultad y enigma: "la soberanía no queda completamente erradicada en virtud del surgimiento de un nuevo arte de gobernar (...) El problema de la soberanía no ha sido eliminado; al contrario, es más agudo que nunca" ((Foucault, p.135). En segundo lugar, el enigmático deseo de Estado. No abordado en el curso, pero recogido en la situación de cursos a partir de una entrevista que comenta el objetivo del trabajo: indagar la formación de lo que llamamos razón de Estado, y la sorpresa que le despertó toparse con un fleco enigmático "que ya no puede resolverse mediante el simple análisis de las relaciones económicas, institucionales o culturales. Hay en ello una especie de sed gigantesca e imposible de reprimir que obliga a volverse hacia el Estado. Podríamos hablar de deseo del Estado" ((Foucault, p.439). Acaso esa parte, renegada en pos de una historia de la razón gubernamental, sea uno de los secretos políticos de la obra foucaultiana.

Pero Foucault insiste en lo suyo: "El Estado es una práctica" ((Foucault, p.324). Y nos remite a Pierre Bourdieu. El sociólogo enraíza la razón de Estado en el largo y tortuoso pasaje de la Casa al Estado. Es un modelo transicional, receloso de las linealidades, que intenta pesquisar la mudanza del Estado dinástico al Estado burocrático. Así, con Bourdieu, el peso de la balanza vuelve a caer sobre el Estado, cuya emergencia histórica es pensada a partir de la constitución, no de una racionalidad específica, sino de un campo autónomo, el burocrático, orientado y sostenido por un tipo particular de dominación: simbólica. Variante de la mudanza, nunca del todo acabada, de lo privado a lo público, la dominación y el poder burocrático busca en el Estado el paraguas que cobije sus luchas dirigidas a monopolizar el uso legítimo de los bienes públicos. Bourdieu sostiene que el libro de Thuau versa "sobre la génesis del discurso de la forma razón de Estado como discurso de legitimación que hace que intervenga el principio estatal para justificar las conductas del rey; la aparición de este discurso se funda en la ruptura con la lógica de la casa” (Bourdieu, 2014, p.351). ${ }^{4}$ La frase condensa el enfoque bourdieusiano: el discurso de legitimación de los interesados en postular la universalidad desinteresada del interés público y las relaciones de oposición simétrica entre la casa y el Estado, sus juegos de préstamos e inversiones. En el primer caso, se alude a los escritores gubernamentales (Thuau, 2000, p.264), quienes, encabalgados en lo universal, construyen el Estado como fictio Iuris. A diferencia de Foucault, y en parte de Thuau, Bourdieu, puesto que está influido por Kantorowicz, piensa en los discursos jurídicos, antes que en los libros de consejos y máximas de "los políticos". Se trata, por supuesto, de perseguir el modo de legitimación de una nobleza de Estado, cuyas prácticas, luchas y disputas, estrategias de reproducción, están gobernadas por ese mundo simbólico. En el segundo caso, se comparan los misterios de la casa con los del Estado. La lectura de Los dos cuerpos del Rey adquiere ese sentido: la casa como cuerpo y aquello que la trasciende (Bourdieu, 2014, p.338). La lógica de la casa es ética, entraña una moral; el pensamiento doméstico es moral. La razón de Estado rompe con la moral tradicional al desbaratar el juicio doméstico en su faceta política; ésta es su novedad y su escándalo. La elaboración de una racionalidad y una práctica desligada del sentido común, que siempre encuentra argumentos en la razón casa. El problema, dice Bourdieu, "de la razón de Estado es el problema de la constitución de un mundo aparte arrancado a las leyes del mundo ordinario" (Bourdieu, p.354). Se produce una inversión de las lógicas de validación y se constituye un sujeto que sirve a una realidad que trasciende los intereses domésticos.

Por otra parte, el momento de la razón de Estado revela bien el juego de préstamos entre ambos cuerpos. Los "escritores gubernamentales" defienden, va de suyo, el régimen monárquico, pero ya no lo legitiman meramente en términos del raciocinio doméstico, introducen el principio estatal. La monarquía, el monarca en rigor, habita los dos mundos, los dos cuerpos, facilitando el proceso transicional. Lo mismo sucede con el cuerpo de la noblesse de robe y el cuerpo de funcionarios burocráticos. El secreto de la razón de Estado reside en ese doble movimiento: negación de la "razón casa" y reintroducción de la misma en el seno del Estado moderno -Meinecke, como vimos, lo atisbó en su declinación dualista: la razón estatal no puede despojarse del foro de la conciencia, cuyo soporte es religioso. El fondo turbio de la razón de Estado proviene, detrás del fomento de la moral pública, de la vigencia de la "razón casa”; esto es, de las estrategias de reproducción (medula política de las familias). Bourdieu no es Habermas porque la institución de la razón práctica y la moral pública -consecuencia secular de la razón de Estado- no implica el contraste 
entre el espacio público-democrático y el dominio privado (Bourdieu, p.417-18), puesto que lo público por definición arrastra pertrechos privados. Mantener en secreto su dinámica sistémica -aislando en casos las denuncias de corrupción, que siempre versan sobre el aprovechamiento privado, para sí o para los suyos, de tal o cual posición pública - es crucial para la autonomía del campo estatal-burocrático. La sigilosa razón de Estado ofreció la primera justificación.

Para finalizar, vamos a identificar, brevemente, tres oposiciones frontales al sentido de lopolítico que emerge de la razón de Estado. En primer lugar, la constelación republicana, que retoma los legados aristotélicos y ciceronianos, mentando la vida política libre, bajo el signo de la amistad. La obra de Hannah Arendt es su cifra contemporánea. En segundo lugar, la constelación democrática, en su faceta más radical, cuya saga retrospectiva entreteje los nombres de Maquiavelo, Spinoza y Marx. Como dice Bodei:

en Spinoza cae por tierra la justificación adoptada por los teóricos de la razón de Estado y del disimulo: aquella según la cual la política está constitutivamente reservada a pocos, como ciencia oculta, racionalidad que no debe ser divulgada a una masa por naturaleza irracional, pasional y no idóneo para el autogobierno” (Bodei, 1997, p.139).

En el temor al pueblo y en la necesidad de la obediencia se recuesta la razón de Estado. La política spinoziana los reúne en su crítica a la teología-política, recupera un Maquiavelo republicano y destaca el lado salvaje de la democracia -el más natural de los regímenes políticos- o su devenir contra el Estado. Hay un Marx habitante de esa constelación, como lo mostró Miguel Abensour (1999). Maquiavelo, sin duda, enlaza, y también crea rispideces entre, las dos constelaciones; lo mismo ocurre con La Boétie y la servidumbre voluntaria. En tercer lugar, encontramos lo que devino la fragua de la modernidad: la crítica ilustrada, burguesa, económica y jurídica, a la razón de Estado. Se trata de una crítica en nombre de la sociedad, contracara natural y civil del Estado. La naturalidad de la sociedad, dice Foucault, "se opondrá justamente a la artificialidad de la política, de la razón de Estado, de la policía" (Foucault 2004: 400). En esta última pretendemos centrarnos a causa de su virulenta ofensiva ideológica contra cualquier quiasmo entre el secreto y la política, puesto que, por el contrario, las tradiciones republicanas y democráticas conservaban un reenvío en cuanto sus reflexiones políticas guardaban un lugar de privilegio para la prudencia y la cautela, siempre cercanas en su reticente no decir al secreto; no es el caso de Marx, a quien por eso algunos entrevén con, por lo menos, un pie en esta última constelación. La sociedad burguesa, entonces, emplazada en el derecho y la economía, corroe las razones del Estado. No obstante, antes nos detendremos en un intermezzo sobre pócimas malsanas.

\section{BREBAJES}

El apartado dedicado a las conjuras en los grandiosos Discursos sobre la primera década de Tito Livio (Maquiavelo, 1987) comienza con una justificación: "no he querido dejar a un lado la discusión sobre las conjuras, siendo cosa tan peligrosa para los príncipes y los particulares, pues vemos que por su causa han perdido la vida y el estado más príncipes que en la guerra abierta" (Maquiavelo, p.301-2). En una obra dedicada al vivero libero, hay lugar para las políticas de la conspiración, porque, contina Maquiavelo, "cualquiera puede forjar una conjura contra el príncipe". Se observa el signo de una diferencia: mientras en la guerra abierta, los príncipes están seguros y es el pueblo el que arriesga la vida por su señor, en las conjuras son los príncipes los que están en riesgo y el pueblo permanece, por lo general, al margen de las maquinaciones. En efecto, comenta Maquiavelo, que las conjuras son organizadas por los nobles (no es cualquiera, entonces, el que puede dar muerte al príncipe), quienes se encuentran en el círculo del poder y tienen acceso al poderoso. La guerra abierta es declarada, preparada, calculada; en cambio, las conjuras son secretas, inciertas y peligrosísimas. Los riesgos al tramarlas, ejecutarlas y al después de la ejecución, discurren en torno a la necesidad de sostener un secreto por un período aleatorio, sujeto a imprevistos nunca mensurables por el plan conspirativo. Maquiavelo aconseja a los conjurados con surtidos ejemplos, pero, como se sabe, finalmente orientados hacia un sentido político que, frente al enrevesado tiempo contingente 
-potenciado en los cenáculos de la conspiración-, exige actuar sin vacilaciones, con ímpetu y decisión. Lo mismo para los príncipes, quienes no deben amenazar si no están dispuestos a cumplir sus amenazas (ejecutar es siempre menos riesgoso que intimidar), porque el amenazado, "constreñido a hacer o padecer, se vuelve peligrosísimo para el príncipe" (Maquiavelo, p.303).

Inmersos en una reflexión que reactualiza y retuerce un motivo clásico del pensamiento político occidental alrededor de la "muerte del tirano", de su justicia política y del peligro que entraña, en caso de éxito, de desatar ciclos de venganzas (los griegos lo expusieron en sus tragedias) que impidan fundar o refundar el orden político; advertimos, no obstante, el entramado de una contraposición entre una política abierta y una política secreta; dialéctica entre la publicidad y el arcano, que cifra la medula de lo político.

Anudar la política, la guerra y las conjuras en cuanto variantes posibles para propiciar cambios de regímenes, permite, por la negativa, indagar cómo en los albores del Estado moderno se intentó invalidar jurídicamente las conspiraciones; es decir, tornar la contraposición maquiaveliana entre guerra abierta e intrigas, entrevista a partir de la seguridad del príncipe, en una oposición entre actos jurídicos y actos antijurídicos en el marco del Ius in bello. Maquiavelo cotejaba el hierro y el veneno en términos de eficacia, justificando su casi exclusiva atención al primer medio de dar muerte, porque el segundo "es más peligroso, por ser más incierto, porque no todo el mundo tiene facilidad para suministrarlo a la víctima, y es preciso ponerse en contacto con quien pueda hacerlo, y eso puede resultar peligroso. Además, son muchas las causas por las que un brebaje venenoso puede que no resulte mortal" (Maquiavelo, 1987, p.323-4). Hugo Grocio, por su parte, considera que, desde el derecho natural, si alguien merece la muerte es legítimo matarlo no importa el medio, pero según "el derecho común de las Naciones, nunca estuvo permitido emplear el veneno para deshacerte de los enemigos" (Grocio, 1925, p.85). Nos encontramos en un nuevo terreno, el de la filosofía política del derecho de guerra, que intenta discriminar entre armas lícitas e ilícitas, desplazando la cuestión maquiaveliana de la eficacia. Se trata, ahora, de asociar la guerra abierta con la validez jurídica y moral del asesinato en contextos bélicos, y la conspiración -fraguada siempre en secreto- como un acto de violencia reprimible jurídicamente. El veneno, símbolo fatídico de las conjuras, condensa la relación, moderna, entre justicia y guerra.

"El veneno presenta una dificultad particular. El arma es hipócrita. No se la ve venir. Mata al enemigo por la espalda y lo priva de su libertad de defenderse" (Chamayou, 2016, p.149). El motivo de la prohibición es estrecho y sesgado: consiste en ilegalizar un arma que estaba directamente dirigida a los príncipes. Pero, siguiendo a Chamayou, la racionalización de la prohibición es sugestiva ya que permite atisbar la constitución del paradigma moderno del derecho de guerra a partir de una doble oposición. Por un lado, el tránsito de las guerras justas, concebidas como una punición legítima -sólo uno de los contendientes es justo, el otro debe y merece ser castigado por su injusticia-, típicas del mundo medieval regido por el universalismo cristiano, a las guerras concebidas como un duelo ampliado (Clausewitz, 1968, p.27), que metaforiza la igualdad jurídica de los beligerantes materializada en la igualdad del derecho a matar. La justicia ya no puede ser sustancial, solamente es formal -la guerre en forme-; en ese caso, no importan las razones o las causas de la declaración de hostilidades, ambos contendientes serán reconocidos en igualdad de condiciones, bajo el común paradigma del Ius in bello. ${ }^{5}$ Por otra parte, el modelo del duelo y la igualdad jurídica ungen el derecho a la posibilidad de defenderse, a no ser privado del combate; en consecuencia, es imperativo proscribir las armas que, de facto, niegan tal derecho. El veneno, pertrecho oculto, atenta contra la estructura de reciprocidad en el que está asentado la despenalización del homicidio en un contexto bélico. Así, si la primera oposición radica en el cambio en la noción de justicia -como siempre: de quién decide qué es justo-, la segunda reside en invalidar las conspiraciones como método de guerra y cambio de régimen; iluminar con la luz del derecho las penumbras del secreto, el alma conspirativa de la política. Históricamente, la interdicción del veneno es un corolario ${ }^{6}$ del triunfo político de la estatalidad, es decir, de la pacificación interior y de la formalización jurídica de la guerra exterior dentro del concierto europeo de Estados "post-Wetsfalia” (que, por supuesto, no rige para el resto del mundo en trance de colonización: contra los pueblos no europeos todas las artimañas 
bélicas son válidas en nombre de la civilización cristiana). En efecto, la rigurosa distinción entre interior y exterior, tanto en el plano de la conciencia como en el de la territorialidad, supone invalidar cualquier forma de conspiración (modernamente llamada sedición) e incluso un tratamiento al estilo maquiaveliano, quien veía posible el ataque bélico individual (el mejor modo de mantener la conspiración en secreto) contra el príncipe y su estado. Altri tempi. Ahora, Rousseau, en un pasaje muy citado, afirma que "la guerra no es, pues, una relación de hombre a hombre, sino una relación de Estado a Estado (...), cada Estado sólo puede tener por enemigos otros Estados y no hombres" (Rousseau, 1980, p.34). Así, si se lee bien, la paz perpetua kantiana es menos un corte que un corolario del modelo jurídico de la soberanía.

El nuevo nomos acaba con las conspiraciones, prohíbe las armas hipócritas, estatiza el modelo abierto y frontal del duelo, pero atesora un secreto crucial. El cambio de paradigma guerrero que va en el sentido de publicitar y reglamentar los enfrentamientos; en oposición a la tirania de los valores que habilita cualquier tipo de conspiraciones, se ocupa de ocultar bien el arcano de la soberanía.

\section{ILUSTRACión Y ARCANO}

La racionalización, naturalización e individualización de los derechos hace crujir la escisión entre moral privada y política pblica cuyo soporte teórico era la razón de Estado y su concreción existencial el absolutismo. Producto de las guerras civiles religiosas, el Estado absolutista "privatizó" la conciencia moral individual, de fondo confesional, y edificó el orden en la observancia de las leyes estatales y en la responsabilidad soberana del monarca. Desanudando la fe y la obediencia instituyó la separación moderna entre lo privado y lo pblico. La despolitización de la conciencia entrañó la neutralización política de la sociedad, que comenzaba a ser burguesa. Cecilia Abdo Ferez mostró que en la modernidad temprana el llamado fuero de la conciencia no se constituyó como reducto interior, inviolable, sino que, por el contrario, fue objeto de una introyección de normas jurídicas y prácticas confesionales que, en los albores de la bifurcación entre pecado y delito, intentó retener la unión entre derecho y moral (Abdo Ferez, 2013, pp.28-68). Así, el dualismo entre conciencia y derecho, cardinal en la arquitectura política hobbesiana, se recuesta en el "nido de víboras" de la subjetividad, que la modernidad temprana en cuanto "época de crisis" logra iluminar acaso mejor que el unidireccional racionalismo de tipo cartesiano. En efecto, las relaciones entre sujeto, derecho e individuo moral, uno de los pilares de la autocomprensión moderna, es complejísima - los ensayos de Abdo Ferez tienen la audacia de ingresar en ese laberinto, remitimos a ellos- y escapan a este artículo. Por eso, recortamos, en su versión burguesa e ilustrada, el combate de la sociedad, hábitat del individuo, en nombre de la razón y el derecho natural, la transparencia y la propiedad, contra el artificio barroco de la razón de Estado, que, detrás de esa mascarada, pretende esconder el despotismo del poder protector. Pero el recorte exige un antes. Siempre hay un antes. Con Locke individuo y propiedad se tornan intercambiables y, además, obtienen una legitimación extra-estatal; el espacio de la conciencia comienza a politizarse. La politicidad, va de suyo, del derecho natural de propiedad proviene de su exterioridad respecto al principio estatal. Aquello que había sido, según las tesis estatistas, la garantía de la paz, se vuelve, en una provisoria síntesis moral, contra ese fundamento y contra su garante máximo. Dice Koselleck: "La ilustración emprende su marcha triunfal al mismo ritmo que va ensanchando el espacio privado interior hacia la esfera pública" (Koselleck, 2007, p.57). La marcha triunfal va forjando una sociedad de mercado. Allí, en esa nueva sociabilidad, coagulan lo que con extrema generalidad llamamos el derecho y la economía. No el derecho en general, entonces, sino el derecho de propiedad, indistinguible de la autoconciencia individual -en Hegel sigue estando su más magistral y atroz conceptualización filosófica-, o de la naturaleza humana (¿o no se lastima gravemente la humanitas del hombre cuando es despojado de su propiedad? Y a la inversa: ¿Quiénes son esos vivientes que habitan una tierra sin ley, sin fe y sin propiedad?), cuya legitimidad ya no es estatal sino societal: la sociedad civil -indistinguible desde el Siglo XVIII hasta hoy, mal que le pese al progresismo liberal, del mercado. Pues bien, queremos repasar algunos de los resortes teóricos e intelectuales consagrados 
a defender y promover esa sociedad, para nada clastresiana, contra el Estado, cuyo eje controversial ronda la antinomia entre el secreto y la transparencia.

Adam Smith, el anti-Maquiavelo. Para Pierre Rosanvallon (Rosanvallon, 1999, pp.57-61), no estamos ante el "padre fundador de la economía política", ni frente a un promotor del individualismo posesivo, en la saga de Mandeville, o del laisse faire; Smith es un pensador de lo politico, cuya originalidad radica en el entrelazo, no en la reducción de la primera a la segunda, de la sociedad y la economía, produciendo una síntesis entre vida económica y filosofía moral: la economía es la realización de la política. Rosanvallon emplea la formula marxiana para enfatizar que el ilustrado Smith considera que la economía resuelve por sí misma la cuestión de lo político, esto es, el modo de institución de lo social. Contra cualquier arcana imperii, nos topamos con una apuesta por la transparencia y la auto-regulación social. No es la economía como ciencia específica, sino como ciencia de la totalidad social: la sociedad de mercado precede a la economía de mercado. "Concibiendo la sociedad civil como mercado, Smith revolucionó el mundo" (Rosanvallon, 1999, p.62). Así, lo que no logró la inmensa literatura anti-maquiavélica, lo hizo la novísima ideología económica ilustrada: engendrar un dispositivo que acabe con Maquiavelo y la razón de Estado. La obra de Montesquieu es bisagra, se sabe. De todas formas, el mercado, tal como lo teoriza Smith, posee una fecundidad política impactante. Altera la medula de la histórica disputa entre el "poder" y el "derecho" proyectando un espacio homogéneo, progresivamente desterritorializado; convirtiendo al intercambio mercantil en modelo de interacción para la totalidad social. Su fuerza proviene del utopismo moderno: una sociedad transparente y orientada al futuro. Pero su politicidad adquiere vigor en su oposición no al Estado tout court, sino al principio estatal que regula lo social.

Karl Polanyi (1988) explicó cómo la política estatal mercantilista unificó mercados allanando el camino de la futura sociedad burguesa. Sucesivas intervenciones estatales organizan el mercado. El objetivo es evidenciar la historicidad del mismo, recusar la ideología naturalista de un Homo ceconomicus eterno; sin embargo, sostiene Polanyi: "la sociedad económica nació como algo separado del Estado político" (Polanyi, 1988, p.193). Su filiación, su modelo institucional, se distingue del Estado político, puesto que impugna, aunque pondere un Estado al servicio del mercado, el fundamento político de la sociedad. "Una economía de mercado no puede existir más que en una sociedad de mercado" (Polanyi, 1988, p.126).

Me interesa destacar ese otro modo de legitimación, que pone en entredicho los presupuestos cruciales de la comprensión política del mundo, condensada, aunque de modo polémico, en los escritos de la razón de Estado. La sociedad de mercado es un intento de solución de los problemas que arrastraba la idea política del contrato (Rosanvallon, 1999, p.15): ¿quién instituye lo social? ¿Cómo se regula? Las respuestas políticas, la de Maquiavelo y la de Hobbes, son objetadas en nombre de la sociedad civil, quien sustenta el derecho de propiedad, lo vuelve operativo, y regula el orden sin legislador. En rigor, la ideología económica no es una justificación del enriquecimiento, del individualismo posesivo -Smith defendía la frugalidad y compartía ciertos elementos de la crítica rousseauniana a la sociedad política, teatral y barroca-, ante bien, organiza la factibilidad y validez del entramado social moderno, tras el consumado derrumbe del universalismo cristiano, y en liza con las razones del Estado.

Si Polanyi expone la institución de la sociedad de mercado desde el punto de vista histórico, insistiendo en la catástrofe social que implicó su puesta en marcha y en su imposibilidad fáctica, Rosanvallon se detiene en el rasgo histórico-conceptual de dicha institucionalización. Ambos destacan el sesgo utópico de semejante sociedad; de allí proviene su fuerza y su debilidad. Utopía de la transparencia y de la armonización natural de los intereses. La paradoja que trasluce el cruce entre el sujeto interesado y la armonía natural encuentra un principio de resolución en la primacía de la transparencia. Sea del sentido de la acción, de las formas jurídicas o de los precios, la sociedad de mercado funciona en un marco cristalino. Reglas claras. Podríamos sintetizar: ideología económica = ideología de la transparencia. Y proseguir enumerando sus consecuencias, ya muy recorridas, para la vida política: reducción de la política a la gestión de intereses o a la regulación de los ciclos vitales, intelección de la misma en términos mercantiles, neutralización de lo político. 
Ahora bien, no es muy difícil colegir que hemos elaborado una oposición, aunque no falsa, algo simplista entre la transparencia mercantil y el secreto político. La ideología económica pretende transparentar las oscuridades del poder, que cobija el constitutivo autoritarismo estatal. Sin embargo, la concepción ilustrada y anti-estatal del mercado desplegó sus tentáculos a través de la mística del secreto. Algo intuyó Schmitt: "el concepto de arcanum político y diplomático, incluso allí donde significa secretos de Estado, no tiene ni más ni menos de místico que el concepto moderno de secreto industrial y secreto comercial” (Schmitt, 1985, p.45); pero es en la tesis de un discípulo suyo donde reside la mejor exposición.

Polanyi, como vimos, constataba que la sociedad económica nació como algo separado del Estado político. Koselleck, en Crítica y crisis, hilvana los motivos de esa separación y su politicidad inherente: la destrucción del principio estatal en nombre de la sociedad burguesa. El dualismo entre moral y política, crucial para la legitimación de la soberanía estatal, es vuelto contra ella. Desde el campo despolitizado de la sociedad y la conciencia moral, la ilustración extraerá una nueva legitimidad que, tarde o temprano, se lanzará a la conquista del Estado. El aprovechamiento burgués del dualismo, sus demandas de transparencia frente a la política arcana de los Estados, es decir, la narrativa moral explícitamente a-política, guarda un reverso: "ilustración y secreto surgen desde un principio una junto al otro, como una pareja histórica de gemelos" (Koselleck, 2007, p.64). Heredero, en este sentido, tanto de la razón de Estado como de las tradiciones eclesiásticas, el movimiento de la ilustración se afinca en el secreto. Un tercer secreto. Koselleck analiza dos de los grupos medulares de la ilustración, allí donde la burguesía atempera su talante moral: las logias masónicas y la République des lettres. El enfoque tocquevelliano destaca la explosiva contraposición entre la creciente importancia social de estos grupos y su indigencia política; excluidos del ámbito estatal y declaradamente a-políticos, las instituciones sociales que alientan y representan ganan, por su propio peso y crecimiento, un potencial político indirecto. El movimiento de la ilustración actúa como un portentoso poder político indirecto. Pero esa energía y ese funcionamiento permanecen ocultos, incluso para varios de sus protagonistas: "el secreto encubre el envés político de la ilustración" (Koselleck, 2007, p.70). El objetivo de las logias y los grupos es, a través de protocolos reservados a iniciados, ensanchar los márgenes de libertad frente al Estado absolutista; una libertad moral que, sin embargo, invierte el argumento hobbesiano: "en lugar de protección por medio del Estado surge ahora la protección frente al Estado” (Koselleck, 2007, p.73). No se trata de la protección del fuero interno, que el Estado absolutista garantizaba, sino de la erección de otro ámbito de socialización, esto es, de validación de prácticas, valores, que no requiere, más bien rechaza, el concurso del principio estatal. Sin enfrentar ni desafiar al Estado, dentro de su espacio pacificado, la burguesía socava, en sordina, las bases de la legitimidad estatal. Frente a la dominación directa de la soberanía absolutista, la francmasonería funde una armazón social, un escudo, y traza una nueva frontera entre iniciados y legos que progresivamente se transforma en una "sociedad contra el Estado". Su politicidad es indirecta no sólo porque no existe un espacio público-político, sino también porque los masones y los intelectuales de la república de las letras orquestan una crítica moral del poder político. No, por supuesto, en nombre del Príncipe cristiano, cuyos antiguos cultores, por otra parte, si estaban interesados en el poder directo de la iglesia, sino, en cambio, de la razón moral-burguesa. El rechazo moral de las razones políticas de los Estados contiene, in nuce, el desarrollo de una conciencia política superior. Pero antes se suscita el proceso de socavamiento. En primer lugar: "El secreto de las logias quebranta el poder estatal" (Koselleck, 2007, p.79), y en segundo, el triunfo moral e intelectual del reino de la crítica significó que "la alianza de la raison con el Estado existente había quedado destruida” (Koselleck, 2007, p.105). La soberanía política es inmoral

En rigor: la Crítica de la hipocresía es hipócrita porque vela su politicidad. Koselleck opone el secreto de la soberanía al secreto de la Crítica, con una diferencia política a favor del primero. Éste asume la responsabilidad soberana -los artilugios de la razón de Estado no vacían el lugar del poder-; en cambio, la soberanía de la Crítica encubre lo político detrás de la filosofía de la historia. Edifica tribunales morales y decursos inevitables para eludir su responsabilidad pública. Es la respuesta burguesa a la crisis de lo político-estatal en su versión absolutista. Cortejamos la otra: el mercado. La filosofía de la historia y el mercado, poderes políticos 
indirectos por antonomasia, conquistan el Estado sin encontrar un sitio para la soberanía. No la disimulan, como los cultores de la razón de Estado, quienes defendían ese lugar, aunque advertidos de su casi indigerible auto-legitimación imaginaban misterios salvíficos o se encomendaban a la diosa Ananké -que no debe verse como un anticipo de la filosofía burguesa de la historia puesto que ésta se afinca en las novedades conceptuales y temporales del progreso y la revolución que barren con la contingencia consustancial a la raison d'État -, antes bien, desplazan o reniegan del pedestal soberano. Paradójicamente en nombre de la transparencia del mercado, las leyes y del progreso histórico, la ilustración refuerza el arcano de la soberanía, pero lo despolitiza. "El anonimato político de la ilustración se cumple en la soberanía de la utopía" (Koselleck, 2007, p.162).

\section{LO POLÍTICO HOJALDRADO}

El último artículo de Oscar Landi versó sobre el secreto y la política (Landi, 2003, pp.113-125). Tomando como un hecho el sitio ineludible del secreto en la trama societal, Landi encaraba el problema a partir de las tribulaciones de la democracia argentina post 83: el secreto como inhibición de la democracia en un sentido similar a los trabajos bobbianos (2013) de la década del 80 puesto que la preocupación es contigua: el fortalecimiento de la democracia-. La semana santa de 1987, el pacto de Olivos, eran ejemplos de negociaciones oscuras de las elites políticas a espaldas del pueblo, que minaban la densidad democrática y su promesa fundante: la soberanía popular y la deliberación pública. En el contexto devastador de la crisis del 2001 y de una arraigada cultura de la sospecha respecto a la práctica política, Landi, acaso demasiado amarrado a los años dorados de la transición, criticaba el uso elitista del secreto, cuyo sesgo enltima instancia es anti-político, y apostaba por la razón pblica. La apuesta por la luminosidad de lo pblico suponía, en concreto, combatir la legitimidad política del arcano. No el secreto tout court, sino su uso anti-republicano, si se quiere, aquello que el discurso mediático simplificó bajo el lema de "garantizar impunidad". Landi, por supuesto, no es un ideólogo de la transparencia y tampoco pretendo forzar analogías con lo que analizamos anteriormente, solamente aventuro dos puntualizaciones. En primer lugar, las sucesivas reconsideraciones de las relaciones entre política y secreto irrumpen en los momentos de crisis de lo poltico, cuyo cogollo es siempre la cuestión de la representación. Esto es: ¿quién está legitimado para representar el lazo de unión de la sociedad? Observamos que, con distinta suerte, fueron, intentaron ser o son, de forma hegemónica o combinada, la religión papal, el Estado soberano, el mercado autoregulado, la moral burguesa o revolucionaria y la democracia representativa-deliberativa. En segundo lugar, el entrelazo entre el secreto y la política gana intensidad cuando se incorpora el principio de la estatalidad, ausente en el escrito de Landi, puesto que está orientado hacia el meollo democrático en la que subsume la estatalidad. Así queda diluida una pregunta crucial: ¿el Estado es democrático, o "democratizable", o en rigor es la sociedad la que es democrática a partir de la vigencia del principio ordenador de la estatalidad afincado en la representación popular? ¿La vida democrática presupone la crítica a la verticalidad del poder o es la legitimidad de esa verticalidad, la soberanía, la que oxigena la vida democrática?

El quiasmo entre política y secreto parece inferir la existencia del Estado. Los argumentos a favor y en contra de su validez ontológica barruntan el secreto. El trabajo planteó este trayecto cotejando dos situaciones. Por un lado, cuatro reconstrucciones de la estatalidad moderna calibrada en su racionalidad específica. A partir de Meinecke, Thuau, Foucault y Bourdieu -descontando su diversidad intelectual aunque es ella la que vuelve sugerente la comparación- intuimos una constelación en la que el vínculo entre política y secreto sigue operando, en el desgarrador siglo XX, a través de la relectura de la razón de Estado cuyo núcleo de sentido irradia hacia el moderno lazo entre lo político y la estatalidad. El deshilachamiento del lazo hojaldra lo político, lo abre a la interrogación. El discurrir teórico del siglo XX buscó su concepto, anunció su muerte, vislumbró su renacimiento o vuelta, problematizando siempre su anudamiento moderno con el dios mortal. Nosotros agregamos otra hebra indagando estudios dedicados a la razón de Estado, o destacando su lugar en investigaciones genealógicas más amplias: la razón de Estado, bitácora de lo político. También nos detuvimos 
en la estatización de la guerra, cuyo modelo basado en el duelo proscribía la belicosidad secreta de las conjuras. Las guerras son públicas, entre estados, declaradas y acotadas, jamás ocultas ni eternas. Ejemplo histórico de los efectos de la superioridad política de la estatalidad y de la superposición del secreto con el arcano de la decisión soberana que logra monopolizar el Ius ad bellum. Por otra parte, identificamos la respuesta alternativa, acaso no la filosóficamente más contundente, cuyo ejemplo reside en la obra de Spinoza, pero sí la de mayor eficacia y calado histórico-concreto, a las razones del Estado, siempre sospechadas de estar al servicio de la dominación de una elite, en el movimiento de la ilustración cuya cifra es la transparencia: de las relaciones mercantiles, de los contratos jurídicos y del decurso progresivo de la historia. No obstante, el avance de la transparencia transcurría en bambalinas. Koselleck destaca la paradoja, cuya ilación revela el Jano de la ilustración burguesa. Su sigilosa politicidad es anti-estatal pero su devenir Estado neutraliza lo político en favor de la economía, el derecho o la historia. La tradición revolucionaria heredó este Jano. La revolución parece entrañar un deseo de Estado, como apuntaba Foucault, que, sin embargo, disuelve lo político. Tras la consagración histórica de la ilustración, el reino de la Crítica, lo político emergerá siempre hojaldrado y la sospecha acompañará las razones del Estado.

De todas formas, para concluir, la interrogación en torno a la vigencia del lazo moderno entre lo político y el Estado acaso encuentre cause en los debates argentinos "post-2001". Así, las tribulaciones democráticas de Oscar Landi y las preguntas abismales que nos animamos a barruntar hacen sentido con la añeja razón estatal. Su secreto reside menos en la democracia que en la universalidad política del Estado. La política argentina reclama un "deber en pro del Estado", entendido no como prestador de servicios, una clearing office, sino en su radicalidad soberana. Escrutar el arcano de la soberanía, bitácora política argentina, que, enclavada en su legado ilustrado (incluida la complicidad entre populismo y neoliberalismo) conserva un sesgo anti-estatal. ¿Es posible tal conjetura o hay que aventurarse de una vez a pensar políticamente sin Estado? Confieso que dudo. Por eso, dejo la palabra a otros, quienes sí están convencidos de las razones del Estado:

\footnotetext{
En Latinoamérica, nosotros tenemos que seguir pensando y revisar -para decirlo hobbesianamente- qué tipo de organización coactiva vamos a darnos, qué estamos dispuestos a ceder a esa organización coactiva, y cómo se va a organizar la sociedad a partir de allí. No digo "coactiva" en el sentido de "represiva” versión los años 70, sino lo siguiente: cuánto de nuestra alma asamblearia estamos dispuestos a entregar para tener un Estado como el que decimos que queremos tener, cuando vivimos en condiciones distintas de aquellas en las cuales se pensó nuestra estatalidad. Es muy complejo -y está muy idealizado- lo que decimos cuando decimos "la presencia del Estado" o "el retorno del Estado", etc. Porque ahí está pensada solamente la prestación de servicios, pero no la estatalidad en cuanto forma subjetiva, es decir: el espacio que concedemos para que el Estado nos marque. Esto último, que incluye entre otras cosas la obediencia, es la parte menos simpática de la "presencia del Estado (Abad-Cantarelli, 2010, p.202).
}

\section{BiBLIOGRAFIA}

Abad, S., y Canterelli, M (2010). Entrevista con la revista Rio sin orillas, $\mathrm{N}^{\circ} 4$, Buenos Aires.

Abdo Ferez, C. (2013). Crimen y si mismo. Buenos Aires: Gorla.

Abensour, M. (1999). La democracia contra el Estado. Buenos Aires: Colihue.

Acceto, T. (2005). La disimulación honesta. Buenos Aires: El cuenco del plata.

Bobbio, N. (2013). Democracia y secreto. México: FCE.

Bodei, R. (1997). Geometría de las pasiones. México: FCE.

Bourdieu, P. (1997). "De la maison du roi à la raison d'État. Un modèle de la genèsis du champ bureaucratique”, Actes de la recherche en Sciences Sociales, Vol. 118, París: PDF.

Bourdieu, P. (2014). Sobre el Estado. Cursos en el College de France (1989-1991). Barcelona: Anagrama.

Botero, G. (1589-1997). Della Ragion di Stato. Roma: Donzelli Editore

Chamayou, G. (2016). Teoría del Dron. Buenos Aires: Futuro Anterior. 
Clausewitz, C. (1968). De la guerra. Buenos Aires: Círculo Militar.

Curzio, L. (2004). "La forja de la razón de Estado". Estudios Politicos, N 2. Madrid: PDF.

Dotti, J. (2002). Presentación Deus Mortalis, N 1 . Buenos Aires.

Ferrari, G. (1860). Histoire de la raison d'État. http://www.gallica.bnf.fr: PDF.

Foucault, M. (2004). Seguridad, territorio y población. Buenos Aires: FCE.

Goldestein, P. (2013). “Hugo Grotius, teórico moderno de la guerra”. Deus Mortalis, $\mathrm{N}^{\circ} 11$. Buenos Aires.

Grocio, H. (1925). Del derecho de la guerra y la paz. Tomo III. Madrid: Reus.

Koselleck, R. (2007). Critica y crisis. Un estudio sobre la patogénesis del mundo burgués. Madrid: Trotta.

Landi, O. (2003). "El secreto y la política”. Revista Sociedad, N²0/21 Fac. Cs. Soc., UBA. Buenos Aires: PDF.

Guerrero, O. (1989). "Notas sobre la razón de Estado". Ciencia, Vol. 40 N 1. México: PDF.

Maquiavelo, N. (1987). Discursos sobre la primera década de Tito Livio. Madrid: Alianza.

Marchart, O. (2009). El pensamiento politico posfundacional. Buenos Aires: FCE.

Meinecke, F. (1959). La idea de la razón de Estado en la edad moderna. Madrid: Instituto de Estudios Políticos.

Miceli, M. (2011). “Una aproximación al concepto de Razón de Estado en Giovanni Botero desde la teoría política de Carl Schmitt”. Colección, N 11. Buenos Aires: PDF.

Palti, E. (2005). Verdades y saberes del marxismo. Buenos Aires: FCE.

Polanyi, K. (1988). La gran transformación. Madrid: La Piqueta.

Real Alcalá, A. (2011). "La teoría del Estado de F. Meinecke. Modelos de Estado moderno según las doctrinas staatsnation y kulturnation”. Estudios Políticos, $\mathrm{N}^{\circ} 154$. Madrid: PDF.

Rosanvallon, P. (1999). Le capitalisme utopique. París: Seuil.

Rossler, A. (2013). Ed. Dossier “Derecho y Guerra”. Deus Mortalis, № 11. Buenos Aires.

Rousseau, J.J. (1980). Del contrato social. Madrid: Alianza

Schmitt, C. (1985). La dictadura. Madrid: Alianza.

Schmitt, C. (2012). "Ética del Estado y Estado pluralista". Deus Mortalis, N 10. Buenos Aires.

Simmel, G. (1939). Sociología. Estudios sobre las formas de sociabilización. Tomo I Buenos Aires: Espasa Calpe.

Thuau, E. (2000). Raison d'État et pensée politique à l'époque de Richelieu. París: Albin Michel.

\section{Notas}

1 Della ragione de Stato (1589). Primer texto dedicado específicamente a la cuestión, en el que se encuentra deslindado el concepto y su definición: "el conocimiento para fundar, mantener y aumentar un Estado". Para un primera reconstrucción histórica ver Ferrari (1860) Histoire de la raison d'état, para un trabajo contemporáneo ver Miceli Mario (2011).

2 Para situarse allí ver Guerrero Omar (1989) y Curzio Leonardo (2004).

3 Publicado originalmente en 1966, estamos ante un trabajo de historias de las ideas que, en paralelo a los contemporáneos postulados de la escuela de Cambridge, comienza a desconfiar de la coherencia sistémica de las mismas y opta por hallar su sentido en los contextos de discusión, en las razones prácticas de tal o cual argumentación. Puede observarse en el análisis de la recepción de Tácito como emblema de la razón de Estado (Thuau, p.33-54) y en las estrategias metodológicas (Thuau, pp.16-20; pp.166-168). Sin embargo, Thuau participa de cierto consenso en torno a las historias de las ideas y parece disculparse por no tener la posibilidad de estudiar obras sistemáticas sobre el Estado. Francia, a diferencia de Inglaterra con Hobbes u Holanda con Grocio, no las produjo. El pensamiento estatal durante la época de Richelieu, tiempo convulsionado, estaba más atento a la eficacia práctica que a su verdad (Thuau, p.415). Pues bien, esa falencia, algo lamentable, obliga al historiador a zambullirse en una serie de textos menores, sin densidad teórica, pero política e históricamente muy significativos en el tejido de argumentaciones en favor del Estado. Así, el libro de Thuau hace a tientas lo que la metodología de Quentin Skinner pondera, pero sus estudios no siempre cumplen.

4 Una versión acotada y condensada de este proceso que el autor despliega a lo largo de tres cursos entre 1989 y 1991 dedicados al Estado puede consultarse en el artículo "De la maison du roi à la raison d'État. Un modèle de la genèsis du champ bureaucratique" (Bourdieu, 1997). 
5 Para una serie de ensayos dedicados a los cambios en las concepciones del derecho de guerra ver el dossier "derecho y guerra” en Deus Mortalis (2013), N¹1, pp. 237-380.

6 Tomando las palabras de Grocio como parte de la gestación de un consenso pro-estatal, porque, en rigor, el jurista holandés es algo anterior a la época medular de la supremacía estatal. Para un detallado análisis de Grocio como teórico moderno de la guerra ver Goldestien (2013, p.265-308). 